\title{
Abdominal complex muscle in women with stress urinary incontinence - prospective case-control study
}

Bartlomiej Burzynski ${ }^{1}$, Tomasz Jurys ${ }^{2}$, Michalina Knapik ${ }^{3}$, Kamil Burzynski ${ }^{4}$, Paweł Rzymski ${ }^{5}$, Paweł Rajwa ${ }^{6,7}$, Piotr Bryniarski ${ }^{6}$

${ }^{1}$ Department of Rehabilitation, Faculty of Health Sciences in Katowice, Medical University of Silesia in Katowice, Katowice, Poland

${ }^{2}$ Doctoral School, Faculty of Health Sciences in Katowice, Medical University of Silesia in Katowice, Katowice, Poland

${ }^{3}$ Doctoral School, Department of Urology, Faculty of Medical Sciences in Zabrze,

Medical University of Silesia in Katowice, Zabrze, Poland

${ }^{4}$ Urosilesia Physiotherapy Center in Zabrze, Zabrze, Poland

${ }^{5}$ Department of Mother's and Child's Health, Poznan University of Medical Sciences, Gynecologic and Obstetrical University Hospital, Poznan, Poland

${ }^{6}$ Department of Urology, Faculty of Medical Sciences in Zabrze, Medical University of Silesia in Katowice, Zabrze, Poland

${ }^{7}$ Department of Urology, Comprehensive Cancer Center, Medical University of Vienna, Vienna, Austria

Submitted: 11 December 2020; Accepted: 12 April 2021

Online publication: 17 April 2021

Arch Med Sci

DOI: https://doi.org/10.5114/aoms/135708

Copyright $\odot 2021$ Termedia \& Banach

\section{Abstract}

Introduction: This study was designed to assess the percentage share of musculus obliquus externus abdominis, musculus obliquus internus abdominis and musculus transversus abdominis activity among women suffering from stress urinary incontinence using ultrasound imaging.

Material and methods: The study is a retrospective analysis of prospective collected data of 84 women aged 23-62 years. In the study group are women suffering from grade 1 or 2 stress urinary incontinence according to the Stamey classification; the control group consists of women with no micturition disorders. The abdominal muscles' activity was measured by using ultrasound imaging with assessment of muscle thickness.

Results: The analysis of musculus obliquus externus abdominis in anterolateral abdominal wall activity shows a statistically significant difference between study and control groups concerning isometric tension of abdominal muscles $(p=0.012)$ and lower abdomen tension $(p=0.004)$. Women with stress urinary incontinence present higher activity of the musculus obliquus externus abdominis than women in the control group. In the case of the musculus obliquus internus abdominis, statistically significant differences were found during tension of the lower part of the abdomen $(p=0.024)$. Comparison of activity of the musculus transversus abdominis between study and control groups shows a statistically significant difference during isometric tension of abdominal muscles $(p=0.018)$.

Conclusions: The pattern of activity of the assessed muscles differs between the study group and the control group. In the study group, the activity pattern concerns the higher activity of the musculus obliquus externus abdominis and the lower activity of the musculus obliquus internus abdominis and musculus transversus abdominis.

Key words: urinary incontinence, stress urinary incontinence, abdominal muscle, ultrasonography.

\author{
Corresponding author: \\ Bartlomiej Burzynski MD \\ Department of Rehabilitation \\ Faculty of Health Sciences \\ Medical University of Silesia \\ 45/47 Ziołowa St \\ 40-635 Katowice, Poland \\ Phone: +48 792611812 \\ E-mail: \\ bburzynski@sum.edu.pl
}




\section{Introduction}

The prevalence of urinary incontinence in adult women is $25.7 \%$ [1]. Stress urinary incontinence (SUI) occurs when an increase in intra-abdominal pressure, caused for example by coughing or heavy physical work, is accompanied by the involuntary passing of urine [2]. The prevalence of SUI among adult women is $12.6 \%$, and the most important risk factor is obstetric history [1, 3].

The abdominal muscles generate intra-abdominal pressure, thereby leading to leakage of urine in the case of women with SUI [4-9]. Information concerning the co-contractions of the pelvic floor muscles with different abdominal muscles can be found in the literature [4-6, 10-13]. Our experience with patients suffering from different pelvic area disorders confirms that such co-contractions do indeed occur but the dependency existing between the working of the abdominal and pelvic floor muscles is not fully understood. In assessing the abdominal muscles, it must be remembered that these muscles do not all work in the same way, because some of them form the deep muscle cylinder of the lumbopelvic hip complex and are involved in core stability along with the other muscles of the complex, i.e. the pelvic floor muscles and the musculus multifidus lumborum [14].

Assessment of the abdominal muscles at rest and dynamics can be made using the following techniques: ultrasound, electromyography, elastography and magnetic resonance imaging [5, 15-20].

The aim of the present study is to describe the activity of the abdominal muscles - the musculus obliquus externus abdominis (OE), musculus obliquus internus abdominis (OI) and musculus transversus abdominis ( $\operatorname{Tr} \mathrm{A})$ - in women diagnosed with stress urinary incontinence during different volitional activities in comparison with their activity in women with no such disorder.

\section{Material and methods}

The present study is an analysis of prospectively collected data in the medical records of women undergoing treatment at Uromedicus Clinic, Zabrze, Poland in the period from 1 July 2015 to 12 April 2016. The medical records which were analyzed were divided into two groups: a study group and a control group. The inclusion criterion for the study group was grade 1 or grade 2 stress urinary incontinence (according to the Stamey classification) as diagnosed by a gynecologist or urologist (ICD-10: N39.3). Exclusion criteria were as follows: occurrence of chronic diseases such as diabetes, hypertension, neurological disorders, lesser pelvis trauma, previous urogynecological and gynecological surgery (except caesarean sec- tions), previous lumbosacral spine surgery, current lower urinary tract infection, hormonal treatment within the last six months prior to the study. Patients who did not undergo hormonal treatment at all or had been continuing such therapy for at least six months prior to the study were eligible for the study. The control group was created from the medical records of women in whom stress urinary incontinence and other genitourinary system disorders were excluded by a gynecologist or urologist. In order to minimize the potential risk of bias, the control group was age-matched with the study group.

Analysis of medical records included the thickness of the abdominal muscles due to muscle thickness being an index of its activity [14, 21]. The percentage share of the musculus obliquus externus abdominis, musculus obliquus internus abdominis and musculus transversus abdominis in the activity of the anterolateral abdominal wall, both in the control group and the study group, was calculated based on the thickness of muscle measured by means of ultrasound imaging.

Measurement of abdominal muscle thickness was performed during the following activities:

- during the rest position (the patient lying on her back and without muscle tension),

- during isometric tension of abdominal muscles (the patient lying on her back and performing volitional tensing of the abdominal muscles with no change in their length),

- during sucking in of the lower part of the stomach (the patient lying on her back and performing volitional sucking in of the navel towards the spine),

- during pelvic floor muscle volitional tension (the patient lying on her back and performing pelvic floor muscle lifting in the direction of the head),

- during ASLR (Active Straight Leg Raise) tests (the patient lying on her back and raising the straightened left lower leg, then the right leg, $20 \mathrm{~cm}$ from the vertical).

This test allowed assessment of abdominal muscle reflex activity using ultrasound imaging.

Examination of the abdominal muscles was performed using the MINDRAY DP-6600 Digital Ultrasonic Diagnostic Imaging System (Mindray Building, Keji $12^{\text {th }}$ Road South, High-tech Industrial Park, Nanshan, Shenzhen 518057, P.R. China) to measure muscle thickness. For this purpose, a linear probe with a width of $60 \mathrm{~mm}$ (Mindray 75L38EA Ultrasonic Transducer) and using a frequency of $5.0-10.0 \mathrm{MHz}$ was employed. In the medical records of patients which were screened, abdominal muscle assessment was performed using a $7.5 \mathrm{MHz}$ transducer. The measurement of thickness was performed $4 \mathrm{~cm}$ from the origin of 
the musculus transversus abdominis perpendicular to the course of the assessed muscles. This methodology, in which the ultrasound probe is positioned peripherally to the place of intersection of the midclavicular line with the umbilical line, was developed by Hodges et al. [22]. All measurements were performed on the right side, three times. During analysis of the results, the average value of the three attempts was used.

Patients were instructed in the muscle tensing technique during each ultrasound observation. In addition, trial muscle tensing was performed before each measurement in order to verify that patients were able to perform the tensing correctly. In order to minimize the influence of breathing, ultrasound images were recorded at the end of exhalation. In the process of collecting the $a b$ dominal muscle measurements during the abovementioned activities, commands such as "tense" and "release", "raise" and "release", "suck in" and "release" were used.

The point of application of the ultrasound transducer and a specimen ultrasound image on the basis of which muscle thickness was assessed are shown in Figures 1 and 2 respectively.

In order to determine the percentage share of the three muscles in the activity of the anterolateral abdominal wall, both in the control group and in the study group, the following formulae, which use the muscle thickness values, were applied:

- formula for musculus obliquus externus abdominis:

$$
\% O E=\frac{O E}{O E+O I+\operatorname{Tr} A} \times 100 \%,
$$

- formula for musculus obliquus internus abdominis:

$$
\% O I=\frac{O I}{O E+O I+\operatorname{Tr} A} \times 100 \%,
$$

- formula for musculus transversus abdominis:

$$
\% \operatorname{Tr} A=\frac{\operatorname{Tr} A}{O E+O I+\operatorname{Tr} A} \times 100 \%
$$

The reliability of ultrasound measurement has been confirmed by the authors of many academic studies [15, 23-26]. Gnat et al., in order

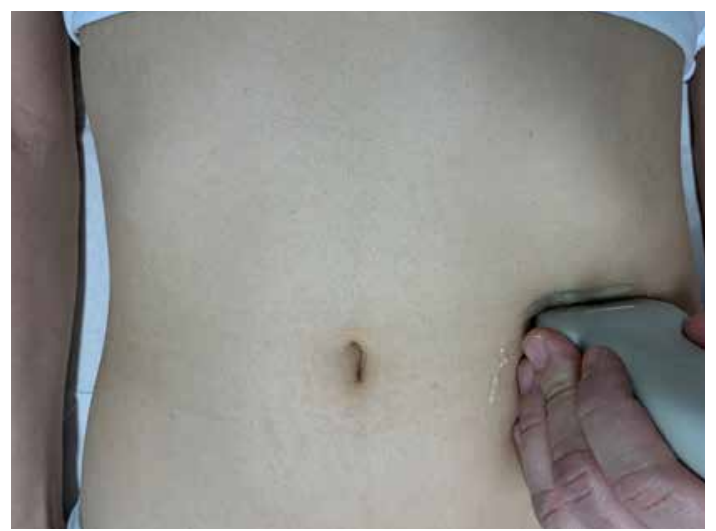

Figure 1. Point of application of ultrasound transducer (source: own material) to verify the reliability of ultrasound imaging, assessed the musculus transversus abdominis in 10 healthy women. They found that the number of repeated measurements necessary to provide an acceptable level of reliability is two in the case of muscle thickness measurement and three in the case of measurement of changes in muscle thickness. They also described the intraclass correlation coefficient for three measurements of musculus transversus abdominis thickness as ranging from 0.96 to 0.98 and for three measurements of changes in musculus transversus abdominis thickness as ranging from 0.80 to 0.90 [27]. McMeeken et al. concluded that the muscle thickness measured via ultrasonography and muscle activity measured via EMG of the musculus transversus abdominis were significantly correlated. The musculus transversus abdominis is located deeply and the ultrasound method has an advantage compared do EMG in evaluating muscle activity $[16,17]$.

The Bioethics Committee of the Academy of Physical Education in Katowice stated that all research procedures were carried out in accordance with the medical experiment design, which contains a positive opinion by Resolution No. 4/2011.

The data collected for the purpose of the present study were arranged in a Microsoft Office Excel 2007 spreadsheet. Statistical analysis was carried out using the STATISTICA Stat Soft program. In order to characterize the analyzed population, basic tools of descriptive statistics were used, i.e. quantitative and percentage descriptions, mean values and standard deviation. For the purpose of comparison of the two groups, Student's $t$-test for two independent samples was used. In the case of no homogeneity of variance, a non-parametric test, the Mann-Whitney U-test, was applied. The Kruskal-Wallis test was applied for comparison of three or more samples. Across the entire statistical analysis, the level of statistical significance was $p<0.05$.

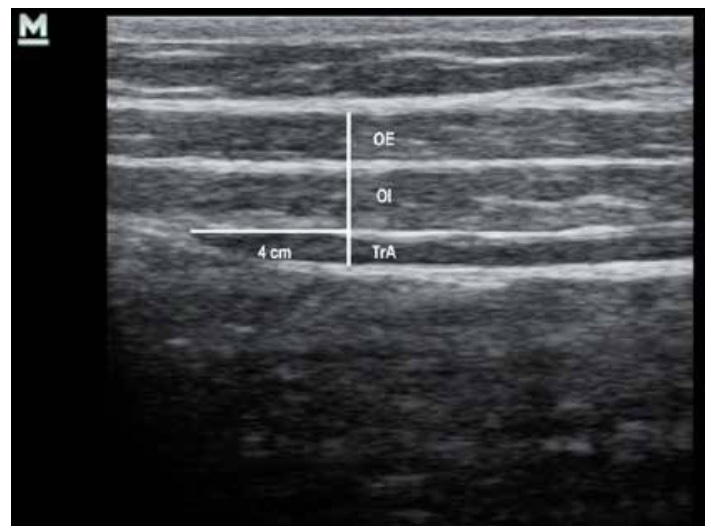

Figure 2. Ultrasound image for muscle thickness assessment (source: own material) 


\section{Results}

The final analysis included the medical records of 84 women who attended the-laboratory of lower urinary tract physiotherapy. The study group consisted of 40 women suffering from stress urinary incontinence and the control group of 44 women with no symptoms of micturition disorders. Physical characteristics of the subject are presented in Table I.

Detailed results of the percentage share of activity of the musculus obliquus externus abdominis, musculus obliquus internus abdominis and musculus transversus abdominis in the study and control group are shown in Table II.

The analysis of percentage share of the musculus obliquus externus abdominis in anterolateral abdominal wall activity shows a statistically significant difference between study and control groups in relation to isometric tension of abdominal muscles $(p=0.012)$ and lower abdomen tension $(p=0.004)$. Women suffering from stress urinary incontinence present a higher percentage of musculus obliquus externus abdominis activity than women in the control group. It is noteworthy that this is the case both in the rest position and in all assessed activities. In the case of the musculus obliquus internus abdominis, statistically significant differences between the study and control groups are found during tension of the lower part of the abdomen $(p=0.024)$. This muscle is more active (as a percentage) in the anterolateral abdominal wall in women in the control group in all assessed activities. Comparison of percentage share of the musculus transversus abdominis in abdominal wall activity between study and control groups shows a statistically significant difference during isometric tension $(p=0.018)$ : during that activity, women without micturition disorders activated this muscle harder (as a percentage). In all the other activities, except the ASLR test of the right leg, the percentage share of the musculus transversus abdominis in anterolateral abdominal wall activity is also greater in the control group.

Table I. Characteristics of the study and control group

\begin{tabular}{|llcc|}
\hline Parameter & & \multicolumn{2}{c|}{ Group } \\
\cline { 3 - 4 } & & Study group & Control group \\
\hline Age & $\bar{x} \pm$ SD & $45.182 \pm 7.795$ & $41.725 \pm 7.666$ \\
\hline Body mass & $\bar{x} \pm S D$ & $68.352 \pm 10.461$ & $63.350 \pm 7.241$ \\
\hline Height & $\bar{x} \pm S D$ & $164.727 \pm 5.169$ & $165.175 \pm 4.367$ \\
\hline BMI & $\bar{x} \pm$ SD & $25.151 \pm 3.389$ & $23.210 \pm 2.702$ \\
\hline
\end{tabular}

Table II. Percentage share of musculus obliquus externus abdominis (OE), musculus obliquus internus abdominis (OI) and musculus transversus abdominis (TrA) muscles in activity of anterolateral abdominal wall in study and control groups

\begin{tabular}{|c|c|c|c|c|c|c|c|}
\hline \multirow[t]{2}{*}{ Muscle } & \multirow[t]{2}{*}{ Group } & \multicolumn{6}{|c|}{ Percentage share of muscles depending on different activity } \\
\hline & & Rest & $\begin{array}{l}\text { Isometric } \\
\text { tension of } \\
\text { abdominal } \\
\text { muscles }\end{array}$ & $\begin{array}{c}\text { Lower abdomen } \\
\text { tension }\end{array}$ & $\begin{array}{l}\text { Pelvic floor } \\
\text { muscle } \\
\text { volitional } \\
\text { tension }\end{array}$ & $\begin{array}{l}\text { ASLR test - } \\
\text { right leg }\end{array}$ & $\begin{array}{l}\text { ASLR test - } \\
\text { left leg }\end{array}$ \\
\hline \multirow[t]{3}{*}{$\mathrm{OE}$} & $\begin{array}{l}\text { Control } \\
\text { group }\end{array}$ & $31.120 \pm 4.412$ & $24.051 \pm 4.583$ & $25.579 \pm 4.527$ & $27.722 \pm 5.930$ & $28.497 \pm 4.899$ & $31.261 \pm 4.137$ \\
\hline & $\begin{array}{l}\text { Study } \\
\text { group }\end{array}$ & $32.464 \pm 4.626$ & $27.073 \pm 6.081$ & $28.376 \pm 4.343$ & $29.047 \pm 5.576$ & $29.919 \pm 5.267$ & $32.250 \pm 4.699$ \\
\hline & $p$-value & 0.177 & 0.012 & 0.004 & 0.294 & 0.207 & 0.313 \\
\hline \multirow[t]{3}{*}{ Ol } & $\begin{array}{l}\text { Control } \\
\text { group }\end{array}$ & $45.878 \pm 3.862$ & $47.027 \pm 5.590$ & $44.980 \pm 4.585$ & $44.090 \pm 5.845$ & $46.751 \pm 4.740$ & $44.363 \pm 4.184$ \\
\hline & $\begin{array}{l}\text { Study } \\
\text { group }\end{array}$ & $45.051 \pm 4.738$ & $46.459 \pm 5.982$ & $42.412 \pm 5.599$ & $43.497 \pm 5.700$ & $44.619 \pm 6.744$ & $43.488 \pm 6.205$ \\
\hline & $p$-value & 0.386 & 0.655 & 0.024 & 0.639 & 0.101 & 0.456 \\
\hline \multirow[t]{3}{*}{ TrA } & $\begin{array}{l}\text { Control } \\
\text { group }\end{array}$ & $23.003 \pm 2.257$ & $28.922 \pm 4.878$ & $29.441 \pm 4.481$ & $28.118 \pm 5.714$ & $24.751 \pm 3.815$ & $24.376 \pm 3.169$ \\
\hline & $\begin{array}{l}\text { Study } \\
\text { group }\end{array}$ & $22.484 \pm .527$ & $26.467 \pm 4.517$ & $29.212 \pm 4.633$ & $27.456 \pm 4.667$ & $25.462 \pm 4.366$ & $24.262 \pm 4.812$ \\
\hline & $p$-value & 0.430 & 0.018 & 0.818 & 0.520 & 0.433 & 0.900 \\
\hline
\end{tabular}




\section{Discussion}

The results of the present study show certain differences in abdominal muscle activity between women with symptoms of stress urinary incontinence and a control group of women with no micturition disorders.

The strengths of the study include the real-time assessment of abdominal muscles in many activities using a reliable tool such as an ultrasound scanner. Summarizing the results presented in this study, several aspects of the analysis of the medical records require a critical view. One such aspect is the relatively small group of analyzed data. Secondly, the inclusion of women contained only those with grade 1 or 2 of stress urinary incontinence symptoms.

In this study, the activity of the musculus transversus abdominis in the study group was generally lower than in the control group, although statistically significant differences were obtained only during isometric abdominal muscle tension. However, in the study by Arab et al., the thickness of the musculus transversus abdominis, which is the basis for the assessment of its activity, was greater in the group of women with stress urinary incontinence than in the control group. The result, as in this study, was not statistically significant, but it indicates a different relationship [28]. Analysis of the activity of the musculus obliquus internus abdominis provided information that in the study group it was generally lower than in the control group, but a statistically significant result was observed only in lower abdomen tension. This time, in a study by Arab et al., similar results were obtained, which also proved lower activity of the musculus obliquus internus abdominis in the group of women with stress urinary incontinence. However, it is necessary to emphasize that in the study conducted by Arab et al., the activity of this muscle was assessed only during pelvic floor muscle tension and that the result was not statistically significant [28]. The assessment of the activity of the musculus obliquus externus abdominis indicates its overall higher activity in the study group, although statistically significant results were observed only in two out of five activities. The authors of this study are not able to compare the results of this muscle activity with the available literature due to the lack of studies of a similar nature. Only Figueiredo et al. found no strong and significant relationships between urinary incontinence and changes in the activity of the musculus obliquus externus abdominis, which is partially confirmed by the results of the present study [29]. In 2006, Jones et al. found that there is a pelvic floor muscle reaction in response to musculus transversus abdominis activity, and drew attention to the fact that this reaction is delayed or does not exist at all among women suffering from stress urinary incontinence. Jones also stated that increased tension of the superficial muscles, at the expense of decrease in deep muscle tension, is a cause of delayed or non-existent reaction among women with stress urinary incontinence [30, 31]. This is also indicated by the results of the present study, which show a greater percentage share of musculus obliquus externus abdominis activity in anterolateral abdominal wall tension among women suffering from stress urinary incontinence as well as a greater percentage share of musculus obliquus internus abdominis activity in the control group.

The results of the present research can potentially be used in clinical practice. In order to perform and conduct the process of physiotherapy among women suffering from micturition disorders, assessment of tension and activity of the anterolateral abdominal wall muscles is necessary. Moreover, there are indications to include elements of treatment focused on tension of the anterolateral abdominal wall in the process of physiotherapy.

This study raises unanswered questions about the possible outcomes of including women with grade 3 stress urinary incontinence in the study group. Also, in the present study, the activity of the musculus rectus abdominis was not assessed. However, it would be worthwhile to extend the study to include measurement of musculus rectus abdominis activity. This would allow assessment of all the anterolateral abdominal wall muscles responsible for global stabilization of the lumbopelvic hip complex, and thereby give a more complete view of the compensatory mechanisms that might accompany stress urinary incontinence among women. The results of our study should be considered cautiously. Certain limitations occurred here due to the cohort study model and some inequalities in SUI and control group characteristics.

The results obtained from analysis of medical records allow us to draw the following conclusions: 1) The activity of the musculus obliquus externus abdominis is more marked in the group of women with stress urinary incontinence symptoms. 2) The activity of the musculus obliquus internus abdominis is more marked in the group of women with no stress urinary incontinence symptoms. 3) The activity of the musculus transversus abdominis is more marked in the group of women with no stress urinary incontinence symptoms. 4) There is a difference in the activity pattern of the anterolateral abdominal wall muscles between the group of women with stress urinary incontinence symptoms and the group of women with no micturition disorders.

\section{Acknowledgments}

The authors greatly appreciate the assistance of Mr Alex Tilbury in the preparation of the English language version of this article. 


\section{Conflicts of interest}

The authors declare no conflict of interest.

\section{References}

1. Mostafaei $\mathrm{H}$, Sadeghi-Bazargani $\mathrm{H}$, Hajebrahimi S, et al. Prevalence of female urinary incontinence in the developing world: A systematic review and meta-analysis A Report from the Developing World Committee of the International Continence Society and Iranian Research Center for Evidence Based Medicine. Neurourol Urodyn 2020; 39: 1063-86.

2. Burkhard FC, Bosh JLHR, Cruz F, et al. EAU Guidelines on Urinary Incontinence in Adults. European Association of Urology 2020.

3. Bierut A, Dowgiallo-Smolarczyk J, Pieniazek I, et al. Misoprostol vaginal insert in labor induction: a cost-consequences model for 5 European countries-an economic evaluation supported with literature review and retrospective data collection. Adv Ther 2016; 33: 1755-70.

4. Madill SJ, McLean L. Relationship between abdominal and pelvic floor muscle activation and intravaginal pressure during pelvic floor muscle contractions in healthy continent women. Neurourol Urodyn 2006; 25: 722-30.

5. Neumann P, Gill V. Pelvic floor and abdominal muscle interaction: EMG activity and intra-abdominal pressure. Int Urogynecol J 2002; 13: 125-32.

6. Rzymski P, Burzyński B, Knapik M, Kociszewski J, Wilczak $M$. How to balance the treatment of stress urinary incontinence among female athletes? Arch Med Sci 2021; 17: 314-22.

7. Hodges P, Gandevia S. Changes in intra-abdominal pressure during postural and respiratory activation of the human diaphragm. J Appl Physiol 2000; 89: 967-76.

8. Cresswell AG, Grundström H, Thorstensson A. Observations on intra-abdominal pressure and patterns of abdominal intra-muscular activity in man. Acta Physiol Scand 1992; 144: 409-18.

9. Junginger B, Baessler K, Sapsford R, Hodges PW. Effect of abdominal and pelvic floor tasks on muscle activity, abdominal pressure and bladder neck. Int Urogynecol J 2010; 21: 69-77.

10. Sapsford RR, Hodges PW, Richardson CA, Cooper DH, Markwell SJ, Jull GA. Coactivation of the abdominal and pelvic floor muscles during voluntary exercises. Neurourol Urodyn 2001; 20: 31-42.

11. $B \varnothing K$, Stien R. Needle EMG registration of striated urethral wall and pelvic floor muscle activity patterns during cough, Valsalva, abdominal, hip adductor, and gluteal muscle contractions in nulliparous healthy females. Neurourol Urodyn 1994; 13: 35-41.

12. Critchley D. Instructing pelvic floor contraction facilitates transversus abdominis thickness increase during low-abdominal hollowing. Physiother Res Int 2002; 7: 65-75.

13. Fabian G, Kociszewski J, Kuszka A, et al. Vaginal excision of the sub-urethral sling: analysis of indications, safety and outcome. Arch Med Sci 2015; 11: 982-8.

14. Hodges PW. Is there a role for transversus abdominis in lumbo-pelvic stability? Man Ther 1999; 4: 74-86.

15. Jhu JL, Chai HM, Jan MH, Wang CL, Shau YW, Wang SF. Reliability and relationship between 2 measurements of transversus abdominis dimension taken during an abdominal drawing-in maneuver using a novel approach of ultrasound imaging. J Orthop Sports Phys Ther 2010; 40: 826-32.
16. McMeeken JM, Beith ID, Newham DJ, Milligan P, Critchley DJ. The relationship between EMG and change in thickness of transversus abdominis. Clin Biomech (Bristol, Avon) 2004; 19: 337-42.

17. Ha SY, Shin D. The effects of curl-up exercise in terms of posture and muscle contraction direction on muscle activity and thickness of trunk muscles. J Back Musculoskelet Rehabil 2020; 33: 857-63.

18. Rzymski P, Skórzewska A, Skibińska-Zielińska M, Opala T. Factors influencing breast elasticity measured by the ultrasound Shear Wave elastography - preliminary results. Arch Med Sci 2011; 7: 127-33.

19. MacDonald D, Wan A, McPhee M, Tucker K, Hug F. Reliability of abdominal muscle stiffness measured using elastography during trunk rehabilitation exercises. Ultrasound Med Biol 2016; 42: 1018-25.

20. Jourdan A, Le Troter A, Daude P, et al. Semiautomatic quantification of abdominal wall muscles deformations based on dynamic MRI image registration. NMR Biomed 2021; 34: e4470.

21. Madokoro S, Miaki H. Relationship between transversus abdominis muscle thickness and urinary incontinence in females at 2 months postpartum. J Phys Ther Sci 2019; 31: 108-11.

22. Hodges PW, Pengel LH, Herbert RD, Gandevia SC. Measurement of muscle contraction with ultrasound imaging. Muscle Nerve 2003; 27: 682-92.

23. Costa LOP, Maher CG, Latimer J, Hodges PW, Shirley D. An investigation of the reproducibility of ultrasound measures of abdominal muscles activation in patients with chronic non-specific low back pain. Eur Spine J 2009; 18: 1059-65.

24. Koppenhaver SL, Hebert JJ, Fritz JM, Parent EC, Teyhen DS, Magel JS. Reliability of rehabilitative imaging of the transversus abdominis and lumbar multifidus muscles. Arch Phys Med Rehabil 2009; 90: 87-94.

25. Koppenhaver SL, Parent EC, Teyhen DS, Hebert JJ, Fritz JM. The effect of averaging multiple trials on measurement error during ultrasound imaging of transversus abdominis and lumbar multifidus muscles in individuals with low back pain. J Orthop Sports Phys Ther 2009; 9: 604-11.

26. Mannion AF, Pulkovski N, Gubler D, et al. Muscle thickness changes during abdominal hollowing: an assessment of between day measurement error in controls and patients with chronic low back pain. Eur Spine J 2008; 17: 494-501.

27. Gnat R, Saulicz E, Miądowicz B. Reliability of real-time ultrasound measurement of transversus abdominis thickness in healthy trained subjects. Eur Spine J 2012; 21: 1508-15.

28. Arab AM, Chehrehrazi M. The response of the abdominal muscles to pelvic floor muscle contraction in women with and without stress urinary incontinence using ultrasound imaging. Neurourol Urodyn 2011; 30: 117-20.

29. Figueiredo VF, Amorim JS, Pereira AM, Ferreira PH, Pereira LS. Associations between low back pain, urinary incontinence, and abdominal muscle recruitment as assessed via ultrasonography in the elderly. Braz J Phys Ther 2015; 19: 70-6.

30. Jones RC, Peng Q, Shishido K, Perkash I, Constantinou CE. 2D ultrasound imaging and motion tracking of pelvic floor muscle (PFM) activity during abdominal manoeuvres in stress urinary (SUI) women. Neurourol Urodyn 2006; 25: 596-7.

31. Jones RC, Peng Q, Shishido K, Perkash I, Constantinou CE. 2D ultrasound evaluation of dynamic responses of female pelvic floor muscles (PFM) to a cough. Neurourol Urodyn 2006; 25: 624-5. 